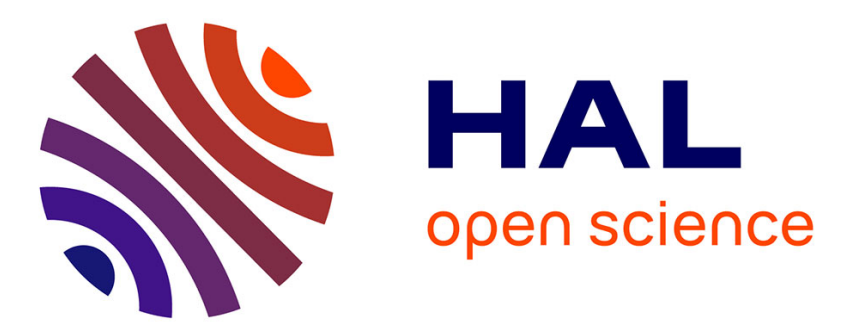

\title{
Application of Local Approach to Quantitative Prediction of Degradation in Fracture Toughness of Steels Due to Pre-Straining and Irradiation
}

\author{
T. Miyata, T. Tagawa
}

\section{- To cite this version:}

T. Miyata, T. Tagawa. Application of Local Approach to Quantitative Prediction of Degradation in Fracture Toughness of Steels Due to Pre-Straining and Irradiation. Journal de Physique IV Proceedings, 1996, 06 (C6), pp.C6-235-C6-242. 10.1051/jp4:1996623 . jpa-00254451

HAL Id: jpa-00254451

https://hal.science/jpa-00254451

Submitted on 1 Jan 1996

HAL is a multi-disciplinary open access archive for the deposit and dissemination of scientific research documents, whether they are published or not. The documents may come from teaching and research institutions in France or abroad, or from public or private research centers.
L'archive ouverte pluridisciplinaire HAL, est destinée au dépôt et à la diffusion de documents scientifiques de niveau recherche, publiés ou non, émanant des établissements d'enseignement et de recherche français ou étrangers, des laboratoires publics ou privés. 


\title{
Application of Local Approach to Quantitative Prediction of Degradation in Fracture Toughness of Steels Due to Pre-Straining and Irradiation
}

\author{
T. Miyata and T. Tagawa
}

Department of Materials Science and Engineering, Nagoya University, 464-01 Nagoya, Japan

\begin{abstract}
Degradation of cleavage fracture toughness for low carbon steels due to pre-straining and irradiation was investigated on the basis of the local fracture criterion approach. Formulation of cleavage fracture toughness through the statistical modelling proposed by BEREMIN has been simplified by the present authors to the expression involving yield stress and cleavage fracture stress of materials. A few percent pre-strain induced by cold rolling deteriorates significantly the cleavage fracture toughness. Ductile-brittle transition temperature is increased to more than $70 \mathrm{C}$ higher by $8 \%$ straining in 500MPa class high strength steel. Quantitative prediction of degradation has been successfully examined through the formulation of the cleavage fracture toughness. Analytical and experimental results indicate that degradation in toughness is caused by the increase of flow stress in pre-strained materials.

Quantitative prediction of degradation of toughness due to irradiation has been also examined for the past experiments on the basis of the local fracture criterion approach. Analytical prediction from variance of yield stress by irradiation is well consistent with the experimental results.
\end{abstract}

\section{INTRODUCTION}

Variation of fracture toughness of materials during in service of the constructions, for instances, degradation due to plastic damage caused by unexpected loading in the earthquake or degradation due to hardening by irradiation in nuclear vessels, should be verified for structural integrity. The great earthquake in Kobe, Japan, 1995 has derived a serious question on ' How to prove the security of buildings, bridges and gas pipe line which are partially, plastically damaged by the earthquake'. Local approach gives a possible and successful methodology to analyze the effects of various factors on toughness through the formulation of toughness in terms of mechanical properties of materials. For the cleavage fracture of steels, maximum tensile stress criterion is generally accepted since the propagation of a microcrack nucleated at second phase hard particles is governed by tensile stress. Incorporation of local stress criterion to the analytical or numerical solution for the stress distribution at the crack tip derives an expression of the fracture toughness in terms of flow and fracture stress of materials as shown by RKR [1] and BEREMIN group [2]. Statistical modelling proposed by BEREMIN gives a rational expression of cleavage fracture toughness for steels, of which brittle fracture obeys a weakest link analogy. The effects of specimen thickness and test temperature on toughness and scatter of toughness can be well explained by the BEREMN model [3-5]. In the present work, simplification of the BEREMIN model for utilization of deterministic information on mechanical properties, such as critical fracture stress obtained as the maximum local stress in notched specimen, has been first examined and confirmed experimentally for more than forty types of low carbon steels. Then, the effect of pre-strain induced by cold rolling on the cleavage fracture toughness has been investigated for two types of high strength low carbon steels. Theoretical prediction on the degradation of toughness and the increase of 
transition temperature has been examined on the basis of the formulation of the cleavage fracture toughness. On the irradiation effect on the toughness, small size specimen tests, sub-size Charpy test or small punch test are recommended to evaluate the toughness. However, size effect in fracture characteristics can not be neglected and reduction in specimen size is limited to maintain a certain degree of constraint. Since plastic constraint effect on the toughness is so significant in the cleavage fracture, it is impossible to simulate the cleavage fracture in plane strain condition by the small punch test. In the present work, quantitative prediction of the embrittlement due to the irradiation has been examined for the past experiments from the variation of the yield stress of the materials.

\section{FORMULATION OF CLEAVAGE FRACTURE TOUGHNESS}

Statistical local approach model [2] incorporated with the HRR stress field at the crack tip derives an expression of fracture toughness for a certain failure probability;

$$
K_{c}=\frac{\mathrm{C}(m, n)}{B^{1 / 4}} \sigma_{y s}\left(\frac{\sigma_{o}}{\sigma_{y s}}\right)^{m / 4}
$$

where $\sigma_{o}$ and $m$ are the scale and the shape parameter, respectively, of the Weibull stress for cleavage fracture. $n$ and $\sigma_{y s}$ are the strain hardening coefficient and the yield stress of material, respectively. $B$ is the specimen thickness and $\mathrm{C}(n, m)$ is a function of $n$ and $m$.

If the cleavage fracture stress can be assumed to be independent of temperature, the local approach model expressed by Eq.(1) indicates that the variation of the fracture toughness with temperature is primarily governed by the variation of the yield stress of the material. Equation (1) gives also theoretical foundation for the correlation between the fracture toughness and mechanical properties of materials obtained in other type of specimens, such as notched round bar specimens.

Validity of the statistical BEREMIN model has been confirmed for the specimen thickness effect on the toughness [6], temperature dependence of the toughness [3] and scatter of the toughness [4]. However, it will take a great number of specimens to prove the validity of the statistical model for a wide range of materials, and statistical model is incovenient for practical application. Present authors have examined to simplify the model to be more deterministic in order to investigate the correlation between the toughness and the flow/fracture properties of material for various types of steels [7]. Critical cleavage fracture stress, $\sigma c$ is defined as the maximum principle stress at the cleavage fracture initiation in notched specimens as shown in Fig. 1. Correlation between the average value of $\sigma c$ and the scale parameter of Weibull stress, $\sigma_{o}$, which are both estimated by FEM, was investigated using $1 \mathrm{~mm}$ radius circumferentially notched round bar specimens as shown in Fig.1. Figure 2 shows the relation between $\sigma_{c}$ and $\sigma_{o}$ for 13 to 20 specimens of seven types of ferrite/pearlite steels with different grain sizes. Although $\sigma_{c}$ should depend on specimen size and geometry, the cleavage fracture stress, $\sigma c$ in $1 \mathrm{mmR}$ notched specimens shows linear proportional relation with the Weibull stress, $\sigma o$. This result indicates that cleavage fracture toughness can be expected to

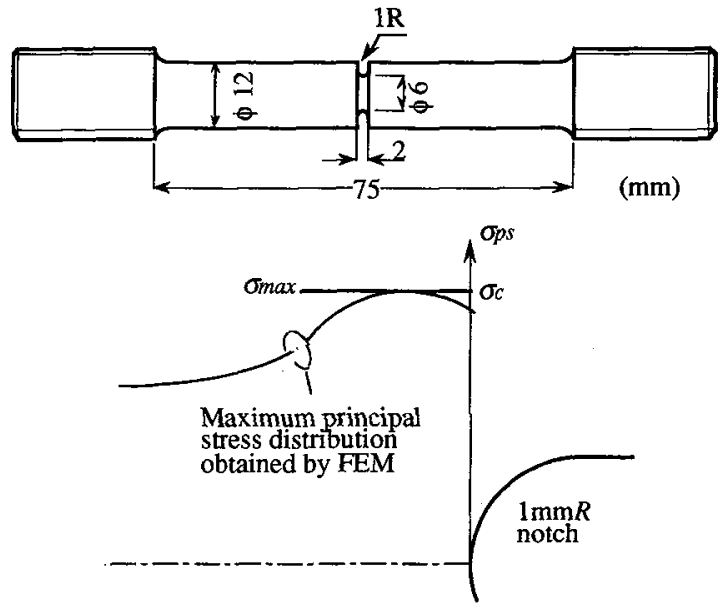

Figure 1: Configuration of notched round bar specimen and definition of cleavage fracture stress $\sigma_{c}$. 
be correlated with the $\sigma c$ obtained in notched specimens. According to the analogy of the statistical formulation, fracture touginess should be expressed as;

$$
K_{c}=\frac{C^{\prime}}{B^{1 / 4}} \sigma_{c}\left(\frac{\sigma_{c}}{\sigma_{y s}}\right)^{\alpha}
$$

Fracture toughness tests and notched round bar tensile test were carried out for more than forty types of steels involving ferritic, bainitic and martensitic microstructure with a yield strength of 250MPa to 1,100MPa. Fracture toughnesses were evaluated at various temperature in terms of $J$ integral using three point bend specimens and CT specimens, and converted to $K c$ values. The cleavage fracture stresses, $\sigma_{c}$ as a local maximum principle stress in $1 \mathrm{mmR}$ notched specimens for the onset of cleavage fracture were evaluated from elastic-plastic FEM analysis for tensile tests at liquid nitrogen temperature and average value of minimum three specimens was taken. Figure 3 shows the relation between $K_{c}\left(J_{c}\right)$ and the cleavage fracture parameter which consists of the yield stress, $\sigma_{y s}$ at the same temperature of the toughness testing and the cleavage fracture stress, $\sigma_{c}$. Exponent coefficient $\alpha$ was decided from the least square approximation for the correlation in each material, since $\alpha$ must be a material constant.

Good correlation, independent of materials, can be observed as is expressed following, though Eq.(2) predicts different proportional constant, $\mathrm{C}^{\prime}$ for each material.

$$
K_{c}\left(J_{c}\right)\left(\mathrm{MPam}^{1 / 2}\right)=\frac{2.85 \cdot 10^{-3}}{B(\mathrm{~mm})^{1 / 4}} \sigma_{c}(\mathrm{MPa})\left(\frac{\sigma_{c}}{\sigma_{y s}}\right)^{\alpha}
$$

Thus, the effects of metallurgical and mechanical factors on the fracture toughness can be discussed through their effects on the flow and fracture properties of materials.

\section{TOUGHNESS DEGRADATION BY PRE-STRAIN}

It is well known that the cleavage fracture toughness of steels deteriorates by pre-straining $[8,9]$. However, degree of deterioration seems to be dependent on the materials and quantitative prediction of deterioration is still difficult due to lack of analytical approach. In this section, experimental and analytical results on the

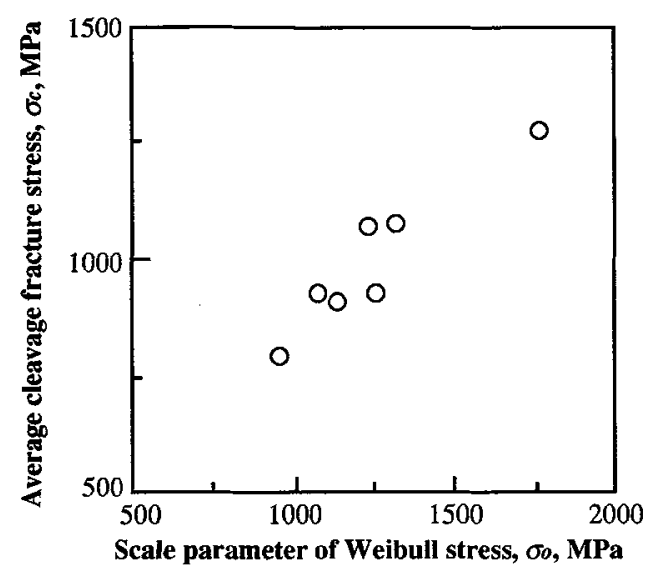

Figure 2: Relation between $\sigma_{c}$ and $\sigma o$ for ferrite/pearlite steels with different grain sizes.

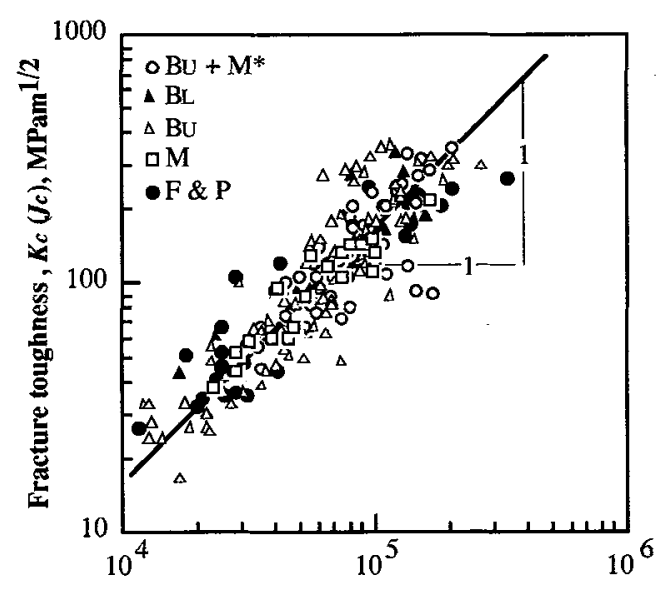

Cleavage fracture parameter, $\sigma_{c}\left(\sigma_{c} / \sigma_{y s}\right)^{\alpha}$, MPa

Figure 3: Relation between fracture toughness and cleavage fracture parameter obtained by round bar specimens. 
effect of pre-strain on the fracture toughness and the transition temperature are discussed as an application of the local approach.

\subsection{Materials tested and experiments}

Materials tested are low carbon steels received as a normalized condition, of which chemical compositions and mechanical properties are shown in Table 1 and Table 2. Pre-strains of 2 or $3 \%$ and 8 or $9 \%$ in equivalent plastic strain were induced by cold rolling. Cleavage fracture toughnesses at various temperature were evaluated in terms of $J_{c}$ for three points bend specimens with $10 \mathrm{~mm}$ thickness in accordance with BS 7448 . Cleavage fracture stress were obtained by notched round bar specimen with $1 \mathrm{~mm}$ radius notch shown in Fig.1. All test specimens were oriented so that the tensile axis coincided with the rolling direction of the plates. To obtain the stress distribution for the notched specimen, axisymmetric finite element analysis with iso-parametric elements was performed using the stress-strain constitutive relations of the materials. The maximum tensile stress at catastrophic cleavage fracture was taken as the cleavage fracture stress, $\sigma$.

\subsection{Results and Discussion}

The effects of pre-strain on the $0.2 \%$ proof stress at room temperature and $-196^{\circ} \mathrm{C}$, and $\sigma c$ at $-196^{\circ} \mathrm{C}$ were shown in Fig.4. The values of $\sigma c$ are the average of results on four specimens. Although it is well known that the pre-strain increases the cleavage fracture stress [2,9-11], small pre-strain has little influence on the cleavage fracture stress for both steels. Proof stress is increased with the increase of the pre-strain as is presumed from the constitutive equation of the virgin base materials. Figure 5 shows variations of the fracture toughness with temperature. Pre-strain causes deterioration in toughness and increase of the transition temperature. In the case of steel A of which yield ratio $\left(\sigma_{y s} / \sigma_{u t s}\right)$ is low, degree of deterioration are more remarkable than that of Steel B. According to Eq.(3), correlation between the fracture toughness and the cleavage fracture parameter was investigated for base and pre-strained materials as shown in Fig.6. Result in Fig. 6 indicates that the effect of pre-strain can be approximately explained by the local approach and the deterioration in toughness is caused by the increase of the yield stress, that is, the hardening of the materials since the cleavage fracture stress is little influenced by the pre-strain. Provided that the cleavage fracture

Table 1: Chemical compositions of steels tested (mass \%)

\begin{tabular}{cccccc}
\hline & $\mathrm{C}$ & $\mathrm{Si}$ & $\mathrm{Mn}$ & $\mathrm{P}$ & $\mathrm{S}$ \\
\hline Steel A & 0.19 & 0.48 & 1.52 & 0.025 & 0.005 \\
Steel B & 0.16 & 0.44 & 1.42 & 0.020 & 0.004 \\
\hline
\end{tabular}

Table 2: Mechanical properties of pre-strained steels and their materials' codes.

\begin{tabular}{cccc}
\hline Material's code & Plastic strain (\%) & $\sigma_{y s}(\mathrm{MPa})$ & $\sigma_{u t s}(\mathrm{MPa})$ \\
\hline Steel A/BM & - & 327 & 557 \\
Steel A/2.8\%CW & $2.3 \sim 3.8$ & 416 & 561 \\
Steel A/8.4\%CW & $8.1 \sim 8.8$ & 547 & 604 \\
Steel B/BM & - & 350 & 519 \\
Steel B/2.3\%CW & $1.9 \sim 2.7$ & 414 & 566 \\
Steel B/9.2\%CW & $9.1 \sim 9.3$ & 590 & 619 \\
\hline
\end{tabular}

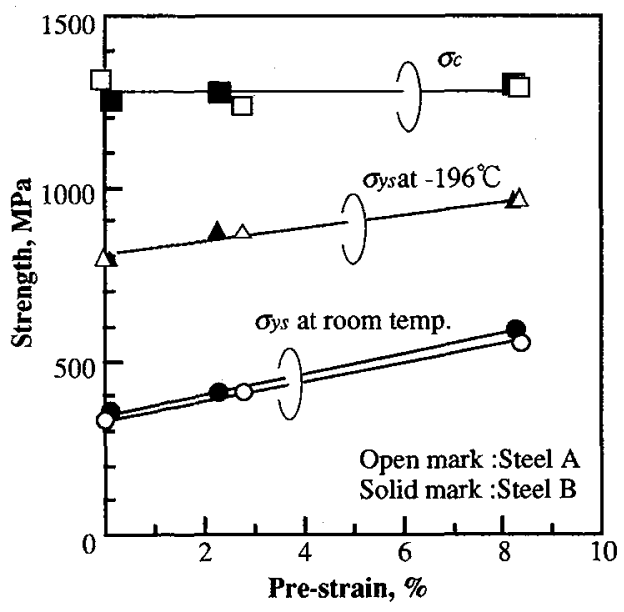

Figure 4: Tensile properties of steels tested as a function on plastic strain. 
stress is kept constant through tha pre-straining and the variance of temperature, the fracture toughness, $K c(J c)$ can be expressed as

$$
K_{c}\left(J_{c}\right)=\mathrm{Cm}\left(\frac{1}{\sigma y s}\right)^{\alpha}
$$

where $\mathrm{Cm}$ is weakly dependent on the constitutive equation of the materials but approximately should be a
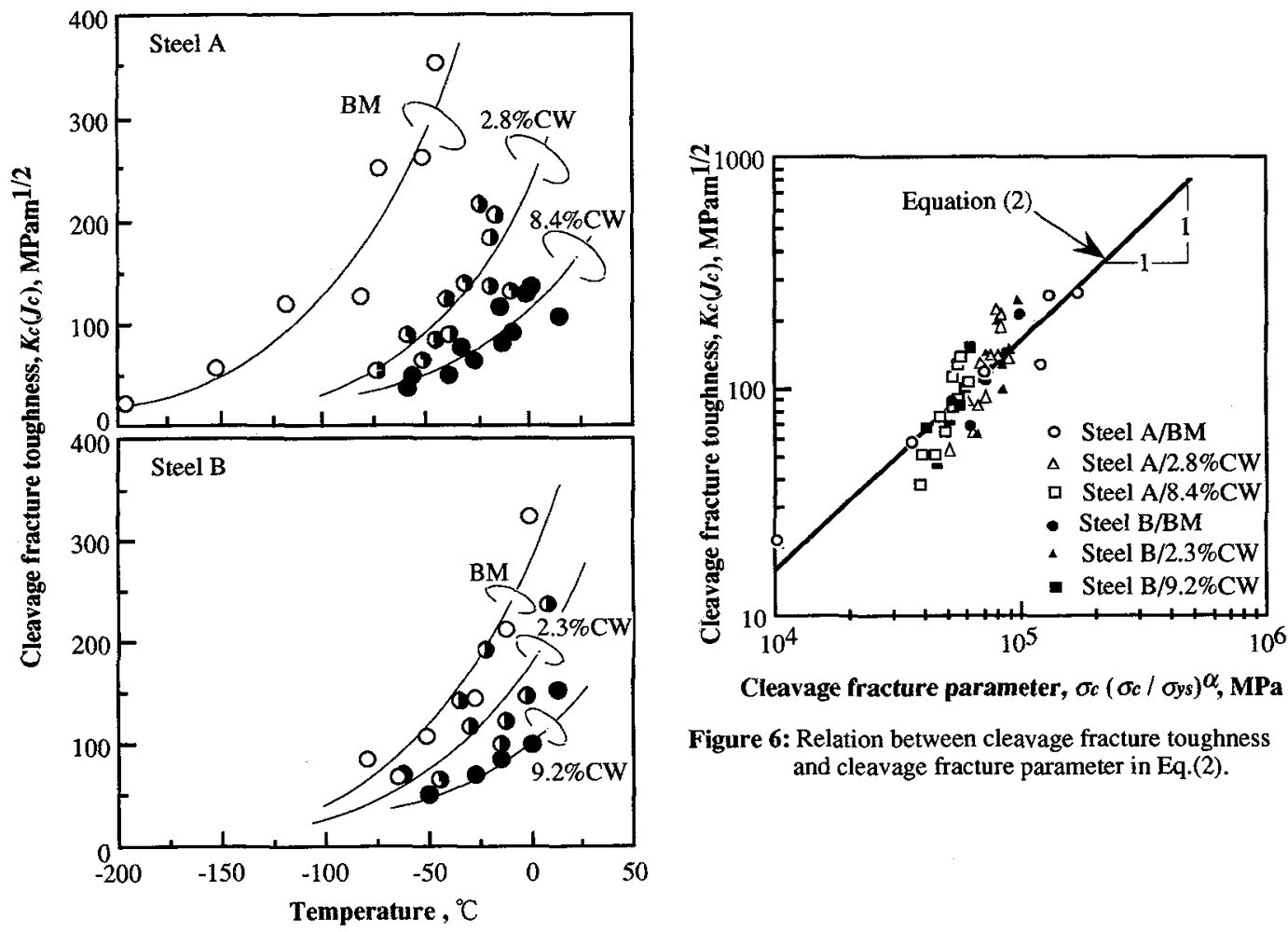

Cleavage fracture parameter, $\sigma_{c}\left(\sigma_{c} / \sigma_{g s}\right)^{\alpha}, \mathrm{MPa}$

Figure 6: Relation between cleavage fracture toughness and cleavage fracture parameter in Eq.(2).

Figure 5: Temperature dependence of fracture toughness.

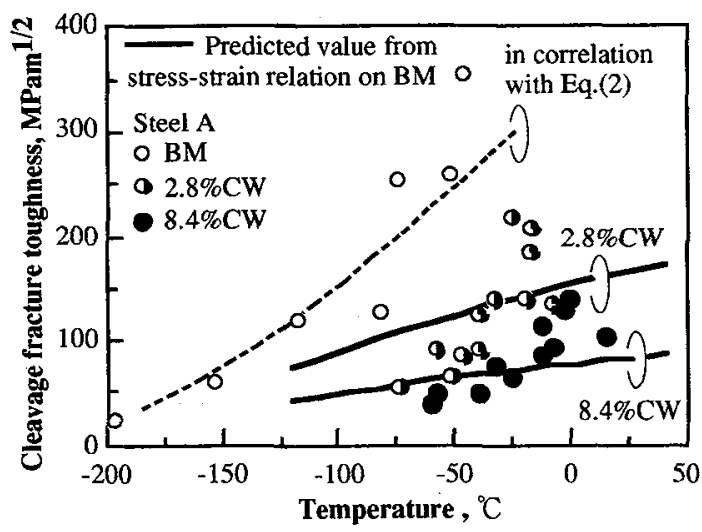

Figure 7: Temperature dependency of fracture toughness after cold work predicted from stress-strain relation on Steel A/BM and experimental values.

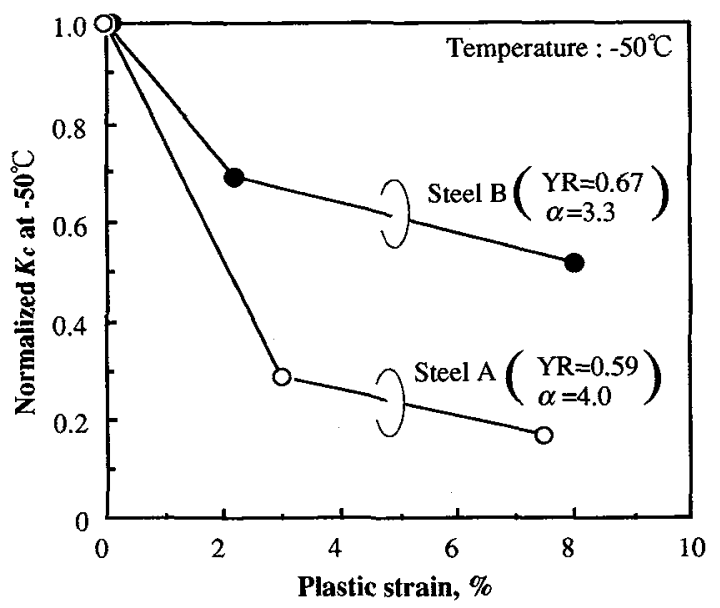

Figure 8: Decreasing ratio of $K c$ at $-50^{\circ} \mathrm{C}$ after cold work obtained experimentally. 
material constant. Since $\alpha$ can be estimated from the temperature dependence of the toughness for virgin material, the effect of pre-strain on the toughness can be quantitatively presumed from the variance of the yield stress. Figure 7 shows the result of prediction of the deterioration from the constitutive equation of virgin materials at room temperature. Temperature dependency of the yield stress for pre-strained materials are presumed from the following relation derived experimentally [12]

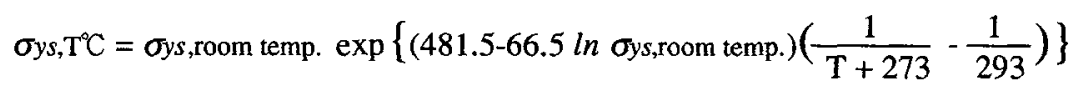

Predicted values only from the data on the virgin base material are approximately coincident with the experimental values. From these results, it can be noticed that the pre-straining in high hardening materials and high toughness materials has large influence on the deterioration in toughness, because the exponent $\alpha$ is related to Weibull exponent $m$, which is generally high in tough materials. Experimental results on steel A and B agree with such analytical prediction as shown in Fig. 8.

\section{EMBRITLLEMENT DUE TO IRRADIATION}

Analogy in the effect of pre-strain on the toughness is applicable to irradiation embrittlement if the metallurgical factors such as microstructure and carbides size and its distribution are not varied with the irradiation. Past experimental data [13] are available to examine the quantitative prediction based on the local approach. One of significant damage due to irradiation is the hardening of materials, and it is known that the hardening is well related to the neutron irradiation index. Figure 9 and Figure 10 show the results on the hardening of A533 steel and deterioration in toughness obtained by Hunter and Williams [13]. If we assume that the cleavage fracture stress is not influenced by the irradiation, the value of $\alpha$ in Eq.(3) are not varied, Eq.(3)

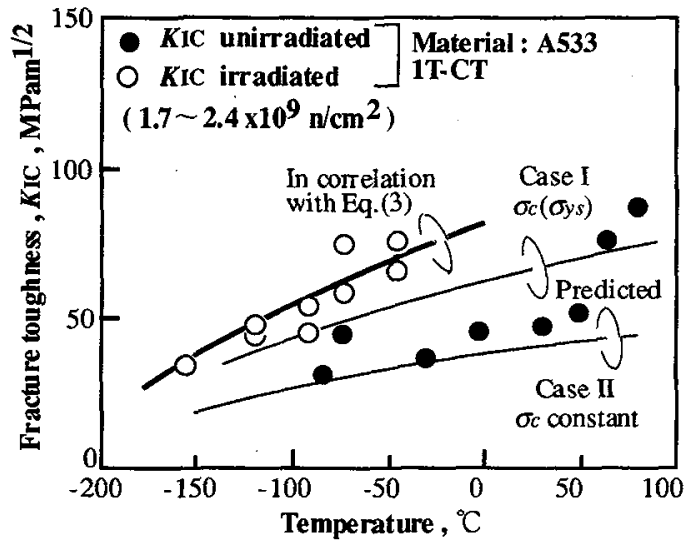

Figure 10: Temperature dependence of fracture toughness before and after irradiation and predicted values based on Eq.(3).

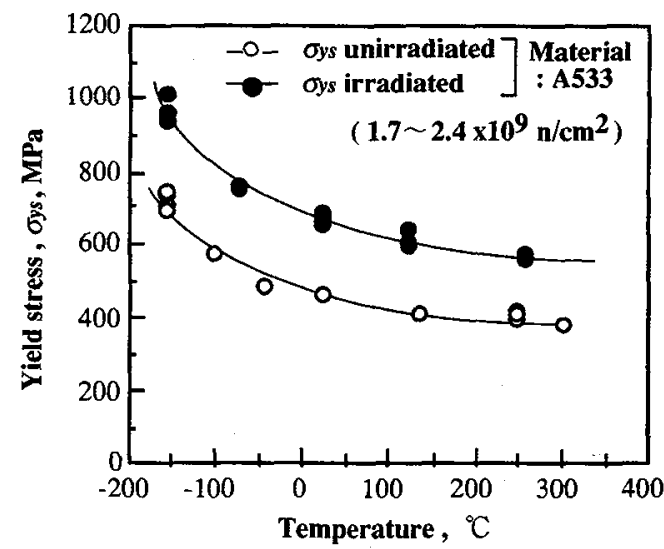

Figure 9: Influence of irradiation on yield stress [13].

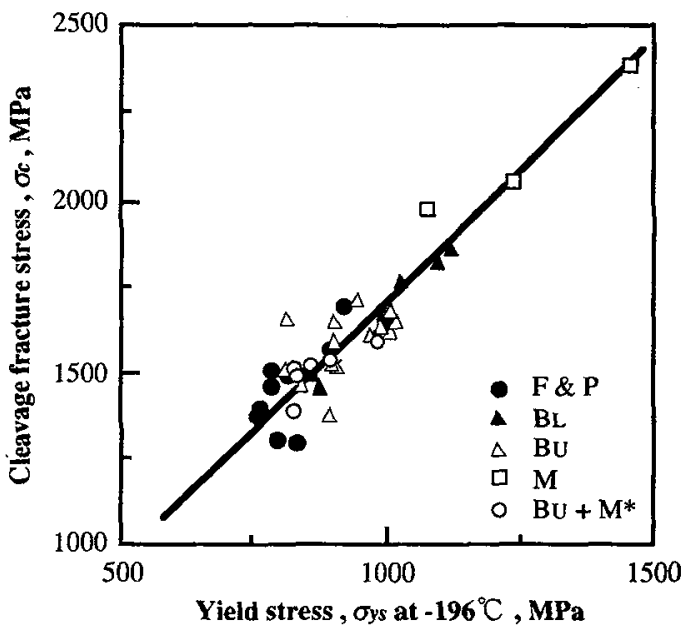

Figure 11: Relation cleavage fracture stress, $\sigma c$ and yield stress, $\sigma_{y s}$ at $-196^{\circ} \mathrm{C}$. 
gives quantitative prediction of embrittlement from the data on the virgin material as is shown in Fig.10 (Case II). On the other hand, increase of dislocation density due to irradiation may suppress dislocation pile up at grain boundary carbides and may increase the cleavage fracture stress. Experimentally, good correlation between the cleavage fracture stress and the yield stress for various types of steels can be obtained [7] as shown in Fig.11. Such relation can be presumed from the Hall-Petch relation to both the cleavage fracture stress and the yield stress. As a first approximation, we assume that the results in Fig.11 can be available to predict increment of the cleavage fracture stress. With the assumption of constant value of $\alpha$, deterioration in toughness can be also predicted from Eq.(3) and the relation in Fig.11 as is shown in Fig.10 (Case I). Experimental results on the toughness lie on the band between the predicted values, Case I and Case II. This result indicates that quantitative prediction of the irradiation damage will be possible only from the variance of the yield stress of the materials insofar as we discuss fracture toughness in the sense of accuracy shown in Fig.10, as is suggested by Parks [14] and Ritchie et al. [15].

\section{CONCLUSIONS}

Formulation of the cleavage fracture toughness in terms of flow and fracture properties of materials was examined on the basis of the statistical BEREMIN model. It is shown that the cleavage fracture toughness can be also expressed in terms of the deterministic definition of the cleavage fracture stress. Degradation of the cleavage fracture toughness due to pre-straining and neutron irradiation was quantitatively investigated on the basis of the local fracture criterion approach. Pre-strain and irradiation both cause the hardening of the material, and hardening causes significant deterioration in toughness, because the toughness is proportional to the inverse of power of yield stress of the material. Successful results on quantitative prediction of the degradation in toughness can be shown for both pre-strain and irradiation effects. Especially on the irradiation embrittlement, it should be noticed that the local criterion approach can offer useful and indirect methodology for prediction of the embrittlement only from the limited data without any fracture tests such as the smail punch test or the half size Charpy impact test.

\section{References}

[1] Ritchie R. O., Knott J. F. and Rice J. R., J. Mech. Physics of Solids 21(1973) 395-410.

[2] BEREMIN F. M., Metallurgical Transaction A, 14A(1983) 2277-2287.

[3] Pineau A., "Review of fracture micromechanisms and a loacl approach to predicting crack resistance in low strength steels", 5th Int. Conf. on Fracture (ICF5), Cannes 29th March-3rd April 1981, Francois D. Eds. (Pergamon press, 1981) pp.553-577.

[4] Wallin K., Engineering Fracture Mechanics 19(1984) 1085-1093.

[5] Miyata T., Otsuka A., Katayama T. and Otake T., "Probabilistic distribution of cleavage fracture stress and scatter of fracture toughness", Defect Assessment in Components -Fundamentals and Application, ESIS/EGF9, Blauel J. G. and Schwalbe K. H. Eds (Mechanical Engineering Pub, 1991) pp.501-515.

[6] Miyata T., Otsuka A., Mitsubayashi M., Haze T. and Aihara S., "Prediction of fracture toughness by local fracture criterion", Fracture Mechanics: 21st sympo. ASTM STP 1074, Gudas J. A. and Hackett E. M. Eds. (American society for testing and materials, 1990) pp.361-377.

[7] Miyata T. and Tagawa T., Tetsu to Hagane 81(1995) 583-588. (in Japanese)

[8] Terasawa K., Ohtani M., Yoshida T. and Terai K.,J. Soc. Naval Arch.Japan 109(1961) 317-335.

[9] Groom J. D. G. and Knott J. F. , Metal Science 19(1975) 390-400.

[10] Knott J. F., J.Iron and Steel Inst., 205(1967) 966-969.

[11] Terasawa K., Ohtani M., Terai K. and Kanatani F.,J. Soc. Naval Arch.Japan 117(1965) 227-236. 
[12] Japan Welding Engineering Soc., Standard Method of CTOD Testing, JWES 1108(1995).

[13] Hunter C. W. and Williams J. A., Nuclear Eng, and Design, 17(1971) 131-148.

[14] Parks D. M., Trans. ASME J. Eng. Mater. and Tech. 98(1976) 30-36.

[15] Ritchie R. O., Server W. L. and Wullaert R. A.Metallurgical Transaction A, 10A(1979) 1557-1570. 